\title{
Commercialization, Diffusion and Adoption of Bioformulations for Sustainable Disease Management in Indian Arid Agriculture: Prospects and Challenges
}

\author{
Ritu Mawar ${ }^{1}$ (D) B. L. Manjunatha ${ }^{1} \cdot$ Sanjeev Kumar $^{2}$ \\ Received: 27 March 2021 / Accepted: 28 June 2021 / Published online: 11 July 2021 \\ (C) The Author(s), under exclusive licence to Springer Nature Switzerland AG 2021
}

\begin{abstract}
Trichoderma spp. is one of the most popular genus of fungi commercially available as a plant growth promoting fungus (PGPF) and biological control agent. More than 80 species of Trichoderma are reported in the literature. However T. asperellum, $T$. harzianum, $T$. viride, and $T$. virens are most commonly utilized as biocontrol agents. Studies were initiated to explore the potential of biocontrol agents in order to develop a cost effective and practical management strategy. Analysis of large number of soil samples collected from western parts of the region led to isolation of native biocontrol agents viz., Trichoderma harzianum, Aspergillus versicolor, and Bacillus firmus from different agricultural systems. These biocontrol agents have proved their antagonistic ability in laboratory tests and field trials. In India, two species of Trichoderma i.e., $T$. viride and $T$. harzianum are commercially registered for usage against soil borne plant pathogens mostly as a seed treatment or soil application. There are published scientific papers on the efficacy of T. asperellum and T. virens in India for suppressing pathogens but these are not yet registered under Central Insecticide Board and Registration Committee (CIB \& RC). This review article focuses on the uses, commercialization and adoption issues of various fungal and bacterial consortium products in sustainable disease management.
\end{abstract}

Keywords Biological control $\cdot$ Biopesticide $\cdot$ Commercialization $\cdot$ Pest management $\cdot$ Soil borne plant pathogens

Ritu Mawar

ritumawar1976@gmail.com

1 ICAR-Central Arid Zone Research Institute, Jodhpur, Rajasthan 342003, India

2 Jawaharlal Nehru Krishi Vishwa Vidyalaya, Jabalpur, Madhya Pradesh 482004, India 


\section{Introduction}

The Indian arid zone covers around 12\% of country's geographical area occupying 31.8 million hectares of land. It covers parts of western Rajasthan, Gujarat, Punjab, Haryana, Maharashtra, Karnataka, and Andhra Pradesh. These areas experience an annual rainfall between 100 and $500 \mathrm{~mm}$ with a coefficient of variation ranging from 40 to $70 \%$. The region is characterized by low and erratic rainfall with extremes of temperature $\left(1-48^{\circ} \mathrm{C}\right)$, high wind velocity, and sandy soils. To sustain livelihoods in arid regions, farmers have developed resilient farming systems consisting of diverse combinations of arable crops, livestock, grasses and fodder crops, agroforestry/multipurpose trees, and horticultural crops as an insurance mechanism against harsh climatic conditions. Cultivation of agricultural crops has been mainly dependent on rains. The principal rain fed crops include pearl millet, green gram, cluster bean, moth bean, cowpea, sesame, and sorghum. These crops are cultivated during rainy season (July-October) after the receipt of first rains. In the irrigated pockets, farmers grow wheat, mustard, cumin, Blond psyllum or isabgol, onion, and garlic. Among these, cumin and isabgol are monopoly crops of this region in India owing to favorable soil and climatic conditions. In last few decades, area under vegetables and fruit crops has increased due to increase in irrigation, access to market, and shift towards commercial agriculture.

\section{Problem, Concern, and Approaches}

Crops grown in the region suffer heavily due to attack of many soil borne plant pathogens. Many factors contribute for their occurrence, which includes concurrent heat and moisture stress, repeated cultivation of susceptible crops in the same field, low moisture holding capacity, and poor microbial population. Macrophomina phaseolina (Tassi) Goid., a soil borne plant pathogen, causes dry root rot or charcoal rot on legumes and oilseeds grown under rain fed conditions [1]. Losses due to wilt (Fusarium oxysporum f. sp. cumini) in cumin alone may reach $40 \%$ [2]. Frequently, growers are left with no alternatives except to abandon cumin cultivation after a few successive years of cropping. In recent years, the arid region witnessed large scale mortality due to attack of Ganoderma in the Indian mesquite (Prosopis cineraria (L.) Druce), locally known as Khejri [3]. This tree is the most important component of the agro forestry systems prevalent in the region [4]. The seedlings of vegetables, fruit crops, and trees raised in nursery are highly susceptible to species of Fusarium, Macrophomina phaseolina, Rhizoctonia solani, Botrydiplodia theoborne, Colletotrichum, Pythium, and root knot nematode causing pre and post emergence mortality, wilt, damping off, and root/stem rots. Often, these account for $20-40 \%$ reduction in seedlings at nursery stage. Several management approaches have been suggested during past four decades. Use of moisture conservation techniques [5], soil solarisation [6], use of cruciferous residues [7], integrating sublethal heating with cruciferous residues [8,9], composts [10], weed residues [11], tolerant genotypes [12], and integrating biocontrol agents in disease management [13, 14]. There has been large upsurge in interest in biological disease control recently, reflecting increasing environmental concern over pesticide use. This interest has been further stimulated by the occurrence of fungicide resistance in some pathogens, and the lack of reliable chemical controls or resistant varieties for some soil-borne diseases. Although the gradual success of such beneficial microbes in agro-ecosystems is indicating that our goal of sustainable agriculture is not an easy task, more challengeable is to design a state of art bioformulation technique 
that not only gives eco-friendly easy-to-use product but also assures good results in field so as to replace the harmful chemicals. The global market and registered companies are also trying to reduce manufacture cost which will definitely help farmers to opt these microbe-based products as suitable alternatives for their crop production.

Arid soils are inhabited by a large variety of flora and fauna, some of which are beneficial to human beings, while the rest are enemies. The soil inhabiting microorganisms that are pathogenic to plants include bacteria, actinomycetes, nematodes, fungi, and some other microbes. Microbes naturally present in soil and root rhizosphere are not always harmful by causing diseases to plants but sometimes serve as biological control agents of various significantly important plant pathogens. Among the soil inhabiting antagonistic fungi, Trichoderma and Gliocladium are widely used for control of diseases in various cultivated crops. Bacterial genera such as Bacillus and Pseudomonas may be potential reservoirs of biocontrol agents for effectively suppressing soil inhabiting root pathogens. The mechanisms through which these bioagents operate are either by direct action against the pathogen i.e., antagonism which includes parasitism, antibiosis, competition, and/or indirectly by reducing host susceptibility (host mediated interaction) and includes exudation, altered rhizosphere, induced resistance, hipovirulence, and PGPR.

Biocontrol agents are very delicate and sensitive to their ecological preferences in terms of temperature, moisture, and salinity. Hence adaptation of biocontrol agents to any new environment (apart from where it was isolated) is a challenge. It has been noticed that a biocontrol agent giving a very good performance under in vitro condition often fails to do so under field conditions. Among the many potential natural enemies of pathogens, biocontrol agents have received significant attention, resulting in development of several microbial-based preparations which are already in commercial production and are in use in crop protection. However, enthusiasm for the use of biocontrol agents needs to be moderated by the realization that only a limited number of microbial agents have been registered as commercial products.

In this article, an attempt has been made to summarize the research carried out on native strains of microbes as biological control agents to suppress the diseases of arid lands and the patents granted to bioformulated products developed by ICAR-Central Arid Zone Research Institute, Jodhpur. The diffusion and commercialization challenges associated with bioformulations in Indian arid context are also discussed.

\section{History of Bioformulations in Pest Management}

In a complete Integrated Pest Management (IPM) programme, management of insect pest, disease, weeds as well as plant growth must be considered in totality. The use of chemical pesticides, no doubt has led to dramatic improvements in productivity and in turn provided a reliable supply of cheap food therefore, and their use were initially welcomed. Of late, consumers are becoming increasingly concerned both about food quality and of the real and perceived effects of modern farming methods on the fast deteriorating environment. While many of these fears have been exaggerated but there is a consensus that modern petro-chemical inputs based farming is ultimately nonsustainable. As a result, more ecological approaches for enhancing the food production as well as quality are now being researched. Concurrently, research efforts are being focused on use of traditional practices e.g., crop rotation, inter and mixed cropping, organic amendments, and summer ploughing. Many of these practices are also successful in managing pest and diseases. Therefore, efforts were also initiated to integrate 
these practices in improving the disease management in any farming system. The role of microbes in sustainable agriculture has provided new vision to agro-economy, and one of the direct benefits is the reduced reliance on chemical fertilizers and pesticides as the continuous application of these chemicals not only showed deleterious effects on agro-ecosystems but also resulted in health risks to humans and animals. Consequently, use of microbe based formulations specific to targeted pathogen offer an ecologically sound and effective solution to any disease. They pose less threat to the environment and to human health. The advantages of using microbe based formulations (in place of chemicals) are based on these factors: (i) Ecological benefit: inherently less harmful on environment; (ii) Target specificity: designed to affect only one specific disease, insect pest or a few target organisms; (iii) Environmental benefit: often effective in very small quantities and often decompose quickly, thereby resulting in lower exposures and largely avoiding the pollution problems; (iv) Suitability: when used as a component of IPM programs, microbe based formulations can contribute greatly.

In last few years, the development of microbial biostimulants or biopesticides for enhancing plant growth and disease eradication has emerged as an alternative, but a broader aspect of their application as biostimulant products has remained in infancy especially in developing countries. At the economic and social level also, this climate friendly strategy is facing many hurdles and lagging far behind their competitors, the synthetic fertilizers and pesticides. Most of the times, it has been found that bioformulations available for a particular crop do not give good results in field equivalent to those in the laboratory conditions. Various researchers all over the world are continuously engaged in developing bioformulated products which could be easier to use, show enhanced activity toward plant pathogens and may cover more target crops. Whole process of bioformulation development from screening of microbe to product development and its implementation need to be reviewed. Microbe-based formulations also known as bioformulations/biopesticides are more robust than synthetic chemicals as the formulation product of a single microbe may involve direct interactions with pathogens, and many mechanisms take part in disease suppression and plant growth promotion [15].

\section{Development of Bioformulations for Arid Region}

It becomes necessary to isolate and identify some local strains of biocontrol agents and screen them against the pests or pathogens of particular region. Such an identified strain of biocontrol agent will adapt well to the local situation and give a better protection under field conditions. So the studies were initiated to explore biocontrol potential of microorganisms in order to develop a cost effective and practical management strategy in augmenting disease control. Analysis of large number of soil samples collected from different parts of the arid region led to isolation of native biocontrol agents viz., Trichoderma harzianum, T. longibrachiatum, Aspergillus versicolor, A. nidulans, Penicillium oxalicum, Bacillus firmus, B. tequilensis, and Streptomyces mexicanus from different agricultural systems. These biocontrol agents have proved their antagonistic ability in laboratory tests. In the next step, their field efficacy on most commonly grown crops, trees, and their effect on resident microflora was studied in order to ascertain whether any bioagent has adverse effect on native organisms. 


\section{Native Fungal and Bacterial Bioagents}

\section{Trichoderma}

Trichoderma is a promising biocontrol agent and extensively used against the soil borne diseases. It has been used against pathogenic fungi such as Rhizoctonia, Fusarium and Colletotrichum. A number of diseases are reported to be controlled by Trichoderma species. It is effective against both foliar and soil borne pathogens [16]. A heat tolerant strain of Trichoderma has been isolated from arid soils, which was found effective against pathogens like M. phaseolina, Fusarium oxysporum f. sp. cumin, $i$ and $G$. lucidum in several studies conducted in arid region $[4,14,17]$. These studies revealed that population of T. harzianum increased gradually in compost prepared from residues of Prosopis juliflora, Calotropis, and weeds compared to farm yard manure and nonamended controls.

\section{Aspergillus versicolor}

During the course of these investigations, it was frequently observed that population of one species of Aspergillus increased tremendously in residue amended heated soil. When separate laboratory tests were performed, it was observed that this strain was parasitizing Fusarium propagules as well as sclerotia of $M$. phaseolina. Subsequently, detailed studies were initiated to confirm the biocontrol potential of this fungus, which was identified as A. versicolor. Studies related to thermal resistance of $A$. versicolor showed that it was able to survive and multiply even at $65^{\circ} \mathrm{C}[18]$. A positive correlation was observed between time interval and increase in population of $A$. versicolor.

\section{Bacillus firmus}

In the recent past, a novel bacterium, $B$. firmus was isolated from naturally heated cruciferous residue amended soil that showed antagonistic activity against $M$. phaseolina. In dual culture tests, it produced a scarlet pigmentation only against M. phaseolina [14]. Separate dual culture tests were also performed to ascertain the activity of antagonistic bacterium against prevalent soil fungi, Fusarium oxysporum f. sp. cumini and a bioagent $T$. harzianum. However, B. firmus could not inhibit the growth of any of these fungi nor any scarlet pigmentation was observed during interaction. Bacillus spp. is particularly suited for studies on biological control due to its omnipresence in soils, high thermal tolerance, rapid growth in broth culture, and ready formation of resistant spores. They are uniformly distributed throughout the soil rather than being concentrated in the plant rhizosphere. The main characteristics of $B$. firmus includes its thermal tolerance $\left(45^{\circ} \mathrm{C}\right)$, phosphate solubilizing nature, compatibility with $T$. harzianum, increased nodulation, plant growth promotion, and potential to colonize roots.

\section{Bioformulated Products of Arid Region}

To introduce an antagonist in the ecosystem and to help it survive, proliferate, become active, and establish itself in a new environment, proper formulations need to be evolved. Once a biocontrol agent is selected on the basis of its potentiality and production of biomass, then suitable formulation development becomes the major concern. Formulation of antagonist 
biomass in suitable form is another step for the success of biological control. The formulation must be easy to handle and deliver at the site of action.

\section{Trichoderma harzianum}

After a series of experiments, efforts were made to develop bioformulated products by utilizing readily available waste materials for preparing compost, inert carrier, and farm yard manure with suitable moisture where this bioagent could survive for a period of 120 days. The bioformulated product was named as Maru Sena 1. Maru sena 1 can be used for legumes, oil seed crops, vegetables, and seed spices, especially cumin. Inoculation can be done through seed treatment ( $4 \mathrm{~g} / \mathrm{kg}$ seed) and soil application ( $1 \mathrm{~kg}$ with $50 \mathrm{~kg} \mathrm{FYM})$ as well as root dips for vegetable seedlings. T. harzianum has separately shown effectiveness in reducing incidence of charcoal rot on rain fed crops like clusterbean, cowpea, sesame, green gram, and moth bean. This strain was also found effective in reducing incidence of wilt caused by Fusarium oxysporum f.sp. cumini on cumin as seed and soil treatment. Till now thousands of packets of this product have been made available to the farmers for demonstrations of Kharif and Rabi crops including clusterbean, green gram, moth bean, cowpea, sesamum, groundnut, chickpea, and cumin.

\section{Aspergillus versicolor}

Bioformulation of $A$. versicolor in a mixture of sterilized neem compost and talc was prepared, which was able to maintain viable propagules of $A$. versicolor for more than 120 days. The bioformulated product was distributed to selected farmers, as Maru Sena 2. Data gathered from Fusarium infested fields of farmers where 10-15\% reduction in wilt incidence was recorded, indicated that bioformulated product could maintain aggressiveness of the biocontrol agent. Use of $A$. versicolor has an additional advantage in hot arid region due to its thermal resistance (up to $65^{\circ} \mathrm{C}$ ) and ability to survive under low soil moisture conditions. Subsequently, demonstrations were undertaken at farmers' field in different seasons where pronounced reduction in wilt incidence (1.0-5.2\%) in cumin was recorded (Singh et al. 2012). This native bio-control agent was successful in establishing itself in soil as recorded by calculating colony forming units $\left(10^{6} \mathrm{CFU} /\right.$ soil $)$. It releases many types of metabolites helpful in growth promotion of plant by showing antagonistic action against soil borne pathogens. In spite of all these positive properties, there are some ailing effects of this strain. It produces mycotoxins, which are harmful to both plants and human beings. It causes aspergillosis, a lung infection in human beings and in plants it is responsible for causing mycotoxin contamination, which reduces food value. Therefore, proper research data needs to be generated before it can be recommended for crop protection in the region.

\section{Bacillus firmus}

Many locally available on-farm wastes were evaluated to select food substrates that can improve the shelf life of $B$. firmus for a reasonable period. Our efforts successfully culminated in identifying a suitable food substrate, which was combined with carrier to retain adequate moisture in the bioformulated product so that bacterium could survive for a period of 180 days. The product designated as Maru Sena 3 was made available for distribution to the farmers. The technology was validated after developing bio-formulated products and their efficacy was 
demonstrated at growers' field to disseminate this eco friendly and easy management strategy in the region [19]. Field demonstrations were carried out at adopted villages of the Institute's Krishi Vigyan Kendra (Farm Science Center dedicated for extension activities). Effectiveness of seed coating with bio formulated product of $B$. firmus on incidence of dry root rot and seed yield of cluster bean, moth bean, and sesame were demonstrated at grower's field during last 10 years. The percent increase in seed yield just by seed treatment ranged from $13.3-23.5 \%$ in all legumes and oil seed crops in different demonstrations. These products are made available for the farmers through Agricultural Technology Information Center (ATIC: Single window delivery mechanism) of the institute. In the last 5 years, hundreds of hectares have been sown with bacterium coated seeds. Farmers are getting positive response in checking incidence of dry root rot in rainfed crops of arid region namely, cluster bean, cowpea, green gram, mothbean, and sesame. The process of developing bioformulated product of these biopesticides has been patented in order to put these products for commercialization for wider adoption among growers. A patent "Bioformulation of a biopesticide and a process for preparing the same" was granted in 2019 with patent no. 309385.

\section{Consortium of Biocontrol Agents}

While working on individual bioformulation, we have focused on their simultaneous use for getting better results, as we know biocontrol consortiums of two or more biocontrol group living symbiotically. Biocontrol consortia have various advantages over single species viz., efficiency, robustness, and modularity. Microorganisms under natural habitats live in communities and some provide benefits to plants. It is unveiled that microbes in small consortia enhance defense signaling cascades leading to enhanced transcriptional activation of several metabolic pathways. With progress in time a sizeable understanding on microbial consortiuminduced plant defenses have been reached. Incidentally, B. firmus operates through antibiosis, while $T$. harzianum kills the mycelium of the pathogen mainly through hyper parasitism. Both the bioagents are compatible in nature. Strategies for developing mixtures of biocontrol agents were envisioned including combining effective organisms against single or more pathogens. It was, therefore, thought worthwhile to develop a consortium of both the native biocontrol agents in the form of a single bioformulated product to improve pathogen control by way of operating different mechanisms of antagonism. Utilizing readily available cheap food substrates and inert materials, a new bioformulated product encompassing both the bioagents was developed, wherein these organisms could survive for a period of 120 days. The product designated as Mishrit Maru Sena, can be stored well at room temperature without losing viability of propagules/spores of both the bioagents under wide range of electrical conductivity. Mishrit Maru sena can be used for legumes, oil seed crops, vegetables, and horticulture crops. Inoculation can be done through seed treatment and soil application as well as root dip for vegetable seedlings. This bioformulated product also improved root colonization of $B$. firmus providing long duration protection to host by pathogen. Its application as seed coating along with incorporation of small dose of compost prepared from radish residues further improved root colonization. Demonstrations of this consortium at growers' field as an essential component of any technology have given encouraging results by way of reducing disease incidence and in increasing yield $[19,20]$. Therefore, technology has been validated at growers' field in order to disseminate this eco friendly and easy management strategy in the arid and semi arid region. Field demonstrations were carried out at adopted villages of the Institute's KVK. There is a huge demand of this consortium among vegetable growers of this 
region for managing soil borne diseases. This product is also made available to the farmers at the institute. A patent on "Consortium of bio-pesticides and bio-formulation comprising same" has been granted in 2019 with patent no. 326803.

Various studies reported that certain biocontrol consortia were unable to show at least comparable effects on plants when compared to their individual applications. One of the major causes for such contrary results may be attributed to incompatibility of the microbes in the mixture with each other. The findings clearly advocate for screening of compatible microbes for development of microbial consortia. The basic objective of developing microbial consortium will fail if the microbes used in the consortium do not have any additive or synergistic effects on disease suppression.

\section{Microbial Consortium in Disease Suppression}

Application of bioagents in consortium may improve efficacy, reliability, and consistency of the microbes under diverse soil and environmental conditions [21]. Use of different species of biocontrol occupy different niches in the root zone and thereby restrict competition among them. Diversity in biocontrol mechanisms offered by each microbial component may also help in enhancing disease suppressiveness. A number of microbial consortia have been developed by many scientists and were tested in different crops in our country. Therefore, in the same stream our consortia prepared with two organisms worked in a synergistic manner. B. firmus operates through antibiosis while $T$. harzianum kills the mycelium of the pathogen mainly through hyper parasitism. It was, therefore, thought worthwhile to develop a consortium of native biocontrol agents in the form of a single bioformulated product to improve pathogen control by way of operating different mechanisms of antagonism for plant disease suppression. The biocontrol consortium activates the antioxidant enzyme activities and the phenylpropanoid pathway leading to accumulation of total phenolics, proline, and pathogenesis related (PR) proteins after the pathogen challenge. The impact of triple microbial consortia consisting of fluorescent Pseudomonas (PHU094), Trichoderma (THU0816), and Rhizobium (RL091) for alleviation of biotic stress in chickpea is through enhanced antioxidant and phenylpropanoid activities [22]. Periodical oxidase and accumulation of total phenol content was higher when challenged with the pathogen compared to the single microbe and dual microbial consortia. Pseuomonas aeruginosa PJHU15, Tricoderma harzianum TNHU27, and Bacillus subtilis BHHU100 as a consortium have been used to assess suppression of soft-rot pathogen Sclerotina sclerotiorum [23]. The triple-microbe consortium and single-microbe treatments showed 1.4-2.3 and 1.1-1.7 fold increment in defense parameters respectively when compared to untreated challenged control. The compatible microbial consortia triggered defense responses in an enhanced level in pea than when the microbes were alone, and provided better protection against Sclerotinia rot. Trichoderma species and fluorescent Pseudomonas spp. have been reported to induce systemic resistance in plants. These biological control agents were tested as a single application and in combination for their abilities to elicit induced resistance in cucumber against Fusarium oxysporum $\mathrm{f}$. sp. radices cucumerinum and in A. thaliana against Botrytis cinerea. The combination of Tr6 and Ps14 induced a significantly higher level of resistance in cucumber, which was associated with the primed expression of a set of defenserelated genes upon challenge with Fusarium. In Arabidopsis, both Ps14 and Tr6 triggered ISR against $B$. cinerea but their combination did not show enhanced effects. In the induced systemic resistance-defective Arabidopsis mutant myb72, none of the treatments protected 
against $B$. cinerea, whereas in the SA-impaired mutant sid2, all treatments were effective. Taken together, these results indicate that in Arabidopsis Ps14 and Tr6 activate the same signaling pathway and thus, have no enhanced effect in combination. The enhanced protection in cucumber by the combination is most likely due to activation of different signaling pathways by the two biocontrol agents.

\section{Next-Generation Bioproducts}

The application of "omics" - technologies has allowed for an enormous progression in the development of so-called next-generation bioproducts [24]. In this field, new tools may have an impact on

- Detection of new bioresources for biocontrol and plant growth promoting agents

- Optimization of fermentation and formulation processes for biological control

- Stabilization of the biocontrol effect under field conditions

- Risk assessment studies for biotechnological applications.

New biocontrol and plant growth promotion agents can be chosen from natural habitats, especially nature conservation areas, are characterized by a high diversity of plants. Due to the correlation of above- and below-below ground variety, a high microbial diversity can be expected [25]. Furthermore, natural habitats have a low number of pathogens, so the general rule of diversity versus pathogenicity would suggest a higher rate of biocontrol and plant growth promotion agents in such environments [26]. Agricultural systems, especially monocultures under intense management often have low microbial diversity with the exception of suppressive soils where the microbial community responds to mono-cultivation by enhancing biocontrol and plant growth promotion bacteria against a specific pathogen [27]. These suppressive soils are also an excellent source of new antagonists as already shown for wheat monocultures [28] and intense sugar beet cultivation [29]. Organically managed systems contain a high proportion of indigenous beneficial in comparison to conventional agriculture $[26,30]$ such as the more exotic bioresource of lichens. These long-living symbiotic metaorganisms often adapt to extreme abiotic conditions and harbor a high proportion of antagonists to protect themselves against fungal parasites [31]. In conclusion, it is important to understand the ecological background of ecosystems and the function of the microbiome therein to select sufficient beneficials. Risk assessments are currently one of the greatest obstacles in bioproduct registration. They are cost-intensive, time-consuming, and often inefficient without considering the specific features of bioproducts. In order to resolve this issue, an intensive network between administration, industry, and research is required. However, the new tools also influence this field and will hopefully lead to not only a higher registration rate, but also to prevent outbreaks by opportunistic pathogens which are sometimes hidden behind antagonists [21]. Moreover, the NGS techniques can be used (i) to detect potential pathogenicity factors and antibiotic resistance at genomics level, (ii) to analyze the mode of action and involvement of metabolites by transcriptomic studies, (iii) to detect bioactive metabolites at genomic as well as transcriptomic level, and (iv) to study the behavior of biocontrol strains in the environment by amplicon libraries or metagenomics. Nextgeneration bioproducts open new windows for sustainable agriculture and are currently visible in industrial and university research topics. A public dialog is required in addition to research 
in order to promote the application of next-generation bio-products in the future for both agriculture and food.

\section{Commercialization: Is It a Challenge in the Field of Bioformulation?}

Commercialization of biopesticides is a multistep process. Though it is easy for any research organization to identify any region specific strain of biocontrol agent, it becomes quite difficult to take it to commercial level of production. Because, any biocontrol agent has to undergo the same processes of registration as like any chemical pesticide which is quite cumbersome, time taking, and costly. Since there is no stability in the effect of biopesticides, farmers always look towards them with doubts. Again, due to the living nature of microbial biopesticides, several factors like temperature, moisture, $\mathrm{pH}$, ultraviolet spectrum, and soil factors adversely affect their survival. The dealers and retailers are also least encouraged to promote biopesticides due to less shelf-life of the product, low profit margin and lack of overall demand among farmers. All these together have resulted in limited adoption of biopesticides among the farmers. However, the diffusion and use of natural and eco-friendly products for pest and diseases and nutrient management in agriculture has increased in recent decades in India on account of several reasons:

1) Climate change and sustainability: Climate change is a threat to agriculture and livelihoods at the global level and India is one of the most affected countries owing to its huge population dependant on agriculture. Excessive and exploitative use of nonrenewable resources such as petroleum products (for production of chemical fertilizers and pesticides) is also a contributing factor for climate change. To "ensure environment sustainability" was one of the eight Millennium Development Goals (MDGs) of the United Nations. All the countries including India are slowly shifting their national policies towards renewable energy sources and eco-friendly green technologies.

2) Self-sufficiency in food production: The country has attained self-sufficiency in food grain production since 1980's. This has enabled India to shift its focus towards quality of food production while sustaining the quantity of current food grain production levels. India's current agricultural policies are aimed at sustainable management of natural resources, sustainability of agriculture, enhancing farm incomes, and eradicating malnutrition. Eco-friendly and green technologies are being promoted to gradually replace/ reduce the chemical intensive agriculture.

3) Increasing awareness among consumers: Increase in quality of life and income levels have enabled the urban population in becoming more aware on the quality of food products being consumed by them. Healthy food and lifestyle has become a priority and diverse and chemical free food is sought after by this section of the society.

4) Increase in area under organic/chemical free agriculture: There is increase in area under organic agriculture in India, which again illustrates the shift towards reduction in use of chemical fertilizers and pesticides as practiced in intensive agriculture. The total area dedicated to organic agriculture in Asia was more than 5.9 million hectares in 2019. There were 1.4 million producers, most of which were in India. The leading countries by area were India (2.3 million ha) and China (over 2.2 million ha). With only $1.3 \%$ of total agricultural land under organic agriculture, India stands fifth among the countries with largest areas of organic agricultural land in 2019 at the global level [32]. There were at 
least 3.1 million organic producers in 2019 at the global level. The countries with the most producers are India (1366226), Uganda (210353), and Ethiopia (203602) [34].

In India, a major technological breakthrough in the field of biocontrol happened when chemical insecticides failed to control Helicoverpa armigera, Spodoptera litura, and other pests of cotton [33]. It was realized that biocontrol is the safest, cost-effective and eco-friendly method to control the widespread resistance of chemical insecticides towards pest insects. Later, biopesticides became a part of IPM which was previously completely based on the use of chemical pesticides [35]. In this context, biopesticides play an important role in promotion of eco-friendly and organic agriculture.

\section{Status of Commercialization, Diffusion, and Adoption of Biopesticides by the Farmers in India}

In India, 15 biopesticides were registered as on 2008 under Insecticides Act (1968), and its market share is only $4.2 \%$ of the overall pesticide market. However, it is predicted to increase at an annual growth rate of $10 \%$ [40]. There are around 400 registered biopesticide active ingredients and over 1250 actively registered biopesticide products in Indian markets [35]. It shows the awareness among the farmers as well as policy support of the government to use the ecologically safe products for pest management. There are 970 biopesticide registrant companies in India by 2020 [36]. However, the commercialization and adoption of the biopesticides is still low in India on account of several reasons:

1) Lack of awareness on its technical know-how and use: Majority of the farmers are not aware on the technical know-how of the biopesticides. Farmers still have many questions regarding biopesticides: (a) What are the different biopesticides available in the market? (b) From where to get these products in time? (c) Are there different products for different crops and diseases? (d) When and how to use them in the crop production cycle? (e) Can they be used in combination with chemical products such as insecticides and fungicides? (f) What is the quantity required? (g) Whether they have to be treated with seed or soil? (h) Are these biopesticides as effective as chemical pesticides? (i) Whether these products are suitable under intensive and commercial agriculture? (j) Are there products available for all pests and diseases? These questions need to be addressed collectively from all concerned stakeholders to overcome the awareness and knowledge gap in use of biopesticides among the farming community. Use of these biopesticides in agriculture also requires skill sets on the part of the farmer. Large scale and regular on-farm trials, on-farm demonstrations, trainings, and capacity building of farmers are crucial to bridge the awareness, knowledge and skill gaps. Despite the benefits associated, the overriding challenge for the biopesticide industry is to live up to the promises and expectations of the end users or the market and public as a whole [34].

2) Low demand and production of the biopesticides: Lack of awareness has resulted in low usage and consequent low demand of these products. The biopesticides are produced and sold in limited quantities by Indian Council of Agricultural Research (ICAR) institutes, State Agricultural Universities (SAUs), and few private firms in India. Lack of experience and quality control are the two major issues plaguing most of the biopesticide products with the private sector [34]. The range of biopesticide products available in the market in 
terms of coverage of crops and diseases is also limited. The biopesticide industry in India is trapped in a vicious cycle of "Low consumption, Low/unstable demand, Low production, Low investment, Low, and unreliable profits". The big private players in the inorganic chemical pesticides and fertilizers market are not willing to invest on biopesticides industry on account of this poor and unstable demand. On the other hand, inorganic chemical pesticides are available at input dealers and retailers' shops in every nook and corner of the country. Increasing the range and accessibility of biopesticides to farming community will occur at the cost of trade-off with the well established inorganic chemicals industry.

3) Lack of consistency in performance: The efficacy of biopesticides has been proved in research farms and organized field trials. The awareness among farming community in general has increased and certain section of farmers is using biopesticides. Farmers using biopesticides have realized that these are ecofriendly but the results are not consistent on account of several reasons. Biopesticides contain living microbes and their count and efficacy is affected by storage conditions, contamination at different stages, proper usage and field conditions. The shelf life of the biopesticides is low as compared to inorganic chemicals. Developing biopesticides that are better performers than chemical pesticides, show broad-spectrum activity, have extended shelf-life, and high tolerance towards environmental factors is a challenging task [37].

4) Regulatory requirements: Many new biopesticide products were developed by ICAR institutes, SAUs, and other R \& D organizations in the country. Some of these technologies were patented illustrating the technical robustness and novelty. In few cases, industry partners have entered into MoUs/licensing agreements with these R \& D organizations for commercialization of these products. However, these firms are finding it difficult to get these products registered for production and sale in the market. It is mandatory for any biopesticide (individual microbial strain or consortia) developed or sold for pest and disease management to be registered with the Central Insecticide Board under the provisions of the Insecticide Act 1968. Manufacturers have to submit information about the biopesticide specifications including chemical composition, source, bio efficacy, toxicology data, packaging, and labeling while applying for registration. Lack of recorded data on these aspects may act as deterrent in registration. R \& D organizations focus on technical efficacy and lack of data on toxicology, health, and environment risks may significantly delay in their registration. Private firms insist that R \& D organizations must develop this data while developing the product itself. However, R \& D organizations are generally equipped with technical competency but since last one decade these organizations are taking extra efforts for addressing regulatory and commercilization issues.

The Central Insecticide Board and Registration Committee (CIB \& RC) demands bioefficacy data for two seasons in two agroecological zones and toxicological studies as basic requirements for any formulation to be used as biopesticide. Therefore, proper planning is required right from $\mathrm{R} \& \mathrm{D}$ stages to develop such data. Toxicological studies from accredited government laboratories in India cost Rs. 2.5 million for one formulation at current prices. Lack of sufficient funds to outsource the toxicological tests has also delayed registration in some cases. Finally, molecular fingerprinting of the microbial culture used in the formulation is required from ICAR-National Bureau of Agriculturally Important Microorganisms. Commercialization of biopesticides and biofertilizers is also governed by the Biological Diversity Act, 2002 especially with regard to equitable sharing 
of benefits and licensing of technologies/products for use outside India. Similarly, biological based nanofertilizers are waiting for commercial production for want of registration under the Fertilizer Control Order, 1985.

5) Quality control: The quality control of the biopesticide products already available in the market needs to be strengthened. Standard protocols and laboratory tests for assessing the quality parameters have been prescribed by the CIB. Government has introduced the Pesticide Management Bill 2008 to monitor and regulate the quality control of pesticides. The increase in demand of biopesticide has resulted in increase in spurious biopesticide products in the market [38]. Lack of quality control may disincentivize the genuine biopesticide manufacturers and potential investors and erode the confidence of the farming community on these products.

6) Valuation and pricing of the technology: Assessing the economic worth of a technology is an important aspect of commercialization. The worth of an IP/technology will be derived from the likely benefits that would accrue to its end-users, and the price will be determined from the extent of the benefits that the $\mathrm{R} \& \mathrm{D}$ agencies would deem to appropriate. The valuation of new technology tends to be very complex, since it involves determining the present value against a future technology or product [39].

7) Cost of biopesticide unit: High costs are involved in establishing and running the lab for production of biopesticides at commercial scale and their quality control. CIB has developed minimum infrastructure guidelines required by the biopesticide manufacturers to issue the manufacturing licenses by state licensing authorities. Quality standards and guidelines must be followed while developing a novel biopesticide product. Quality control parameters such as moisture content, shelf life, $\mathrm{LC}_{50}$, toxicity, and secondary nonpathogenic microbial load have to be met [36].

\section{Technical, Legal, and Policy Issues on New Product Registration}

Even now, the guidelines for registration of biocontrol products draw too heavily on those for chemicals. In some cases it is requested to supply information that is relevant only to chemical products and not to biological products. A biocontrol preparation may sometimes aim at a small market. Being a live entity makes the biocontrol agent unique among control agents, which are usually chemical pesticides. A biocontrol agent is more affected by microclimate factors, and may need different attention regarding shipment, storage, and use. Potential users and distributors should be educated about its handling and need to be convinced about the value of a biocontrol product that is somewhat more difficult to use than standard pesticides. Thus, adoption of biocontrol technologies by growers proceeds more slowly than expected. Indeed, in many places, farmers, agricultural advisors, and even researchers and field personnel were not accustomed to the special handling and use demands that are imposed by the live biocontrol agent. Therefore, special instructions for biopesticide use had to be formulated and then had to be delivered along the chain of marketing, sales and implementation.

While the country continues to battle COVID-19, plant diseases and pests continue to pose threat to food production and farmers livelihood. New pests and diseases continue to surface on plants affecting production. Twenty seven pesticides proposed for ban by Government in May 2020, constitutes almost $25 \%$ of the total generic pesticide market in India. The pesticides along with their constituent 134 formulations are registered to control diseases and other pests. Timing of the notification however, has shaken the industry, farmers and plant protection 
scientists equally, given the uncertainty due to COVID-19 crisis and also due to onset of the Kharif crop season when protection of crop from diseases and pest is considered crucial to ensure crop security. Series of discussions, deliberations and suggestions are engaged into by industry, academia, and scientific associations for a science led decision instead of imposing irrational blanket ban endangering food security and raising cost of cultivation. During last more than five decades, the area under bio intensive IPM remained below 3\% with biopesticides constituting only around 3\% of pesticide market in the country. Present volume of around 27,000 tons of licensed production of registered biopesticides is a miniscule quantity for a large arable area of 142 million hectare in India. Nevertheless, biopesticides cannot qualify as alternative to chemical pesticides but can serve as an important component of disease management. Recently a gazette notification was released about the use of biocontrol agents where some of the genera of biocontrol agents were recently notified as biostimulants by GOI (Gazette Notification 2021). Therefore, chronic toxicology tests may not be required for these formulations, to enable easy and speedy registration of these bio products.

\section{(V) Interventions Required for Speedy Commercialization and Adoption by the Industry and Farmers}

The possible solutions for speedy commercialization of the biopesticides or biostimulants in India are as follows:

1) The R \& D institutions have to collaborate with other stakeholders/organizations from early stages of $\mathrm{R} \& \mathrm{D}$ of product development to develop the data required by the regulatory agencies related to bioefficacy, toxicology, bio safety, and environmental concerns. This will help the potential industries who acquire new technologies to register the products and in production and marketing. ICAR institutes in the country have established Institute Technology Management Units (ITMU) since 2008 supported by 5 Zonal Agro-Technology Management Centers (ZTMCs) at the zonal level and Intellectual Property and Management Unit at the ICAR headquarters, New Delhi governing overall IP, technology commercialization, and policy issues [40]. Public sector organizations in India, including ICAR, license technologies to stakeholders on "nonexclusive basis" only. These ITMUs at all levels have been given the responsibility of facilitation of commercialization of technologies (Fig. 1). However, these ITMU cells are managed by in-house scientific/technical experts. The ITMU staff has to be trained or oriented on the regulatory issues or business professionals have to be hired to run/assist these ITMUs.

2) Government has already initiated several measures to promote the biopesticides and the biofertilizers. The Ministry of Agriculture and Farmers Welfare, the Department of Biotechnology, the Ministry of Science and Technology are actively involved in funding research, development, and marketing of these biopesticides [38]. Ministry of Agriculture and Farmers Welfare is providing necessary guidelines and assistance to as many as 35 commercial companies and 32 integrated pest management (IPM) centers for biopesticide production. The state departments of agriculture and horticulture of Gujarat, Uttar Pradesh, Karnataka, Tamil Nadu, Andhra Pradesh, and Kerala have established numerous advance bio control laboratories [13, 41, 42]. Manufacturers of biopesticides have the option of registering their products either under provisional registration or regular registration under the Insecticide Act 1968. This system reduces commercial barriers to 


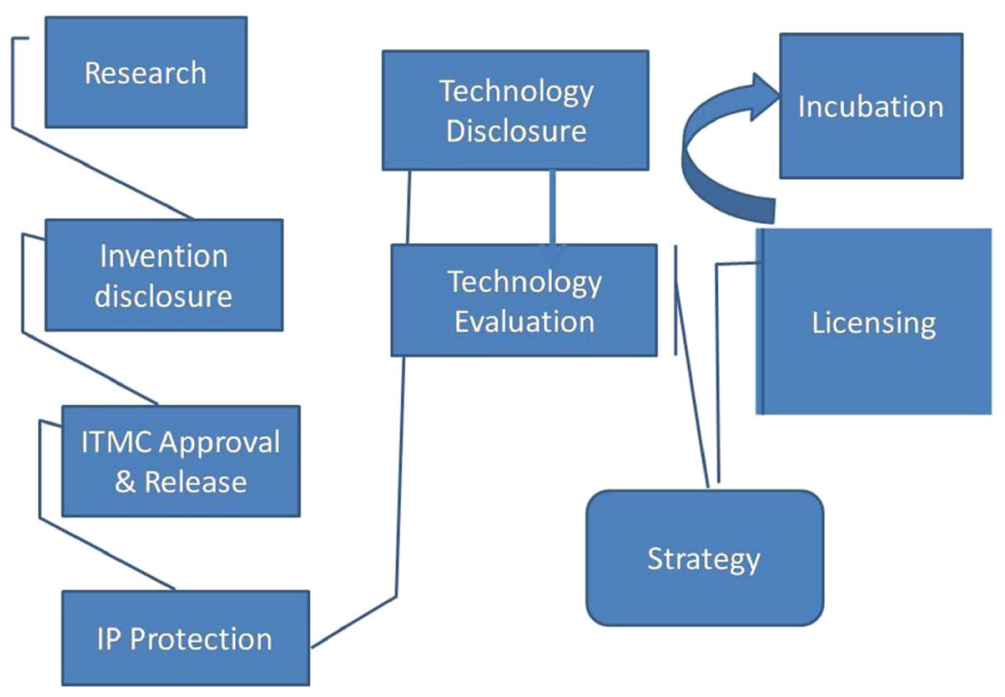

Institutionalized Technology Commercialization Pathway.....

Fig. 1 Institutionalized Technology Commercialization Pathway

product development. The data requirement for temporary registration is less stringent than for regular registration [43].

However, these products have to compete with the well established chemical inputs which are part of agriculture since last 50 years. One mechanism could be to attract and incentivize the big private players in chemical inputs industry to promote these green technologies. Promoting a product requires a well established marketing network, which these industries already have.

3) The gap in knowledge, skill, and attitude of farmers towards biopesticides has to be comprehensively addressed. The state agriculture and horticulture departments have to include these biopesticides and biofertilizers in their package of practices. The front line extension staff of state agriculture and line departments has to be oriented towards these ecofriendly products and suitably address farmers' queries and apprehensions. Extension folders and ready to use study materials and reference materials have to be prepared and made available in all Indian languages. Orientation of academia and researchers also needs to be changed from chemical intensive agriculture to use of alternative sustainable methods and products. The students and agriculture graduates have to be trained on use of these green products through inclusion in course curriculum at different levels. A diploma course on these bio products at SAUs may create a batch of certified para-extension professionals. A fundamental shift in focus at the universities and R \& D organizations governance level from an education, research, and publication based reward system to a commercial activity based one, which entails patenting and licensing of technologies is required [44].

4) Government may also promote start-ups on production and sale of already registered biopesticides. Several ICAR institutes and a few SAUs have recently established Agri Business Incubator Cells (ABIs) to promote start-up agribusiness ventures and commercialization with technological backstopping. However, these ABIs are also managed by in-house scientific/technical experts. Management experts need to be roped in to run/assist 
these units on business model. ABIs can act as bridge between R \& D institutions and entrepreneurs/start-ups/industry to promote these technologies.

5) Farmers are oriented towards chemical inputs based intensive agriculture. Therefore, biopesticides are to be promoted as supplementary and complimentary inputs in the initial phases. Further, governments have to identify regions/areas niche for promotion of organic agriculture and these biopesticides may be promoted in a big way in these areas. For instance, arid and semi arid regions, where the use of chemical inputs is relatively low may be targeted for promotion of these biopesticides. Arid western Rajasthan is a suitable example in this case. Many spice crops of commercial importance are grown in the region, including cumin, which is exported. Government of India has identified cumin crop for Jodhpur district in Rajasthan state under the new One District One Product scheme [45]. Organic production of cumin may be incentivized in the region. However, the availability of range of biopesticides has to be ensured.

6) The production of the already registered biopesticides has to be decentralized using licensing/sublicensing and other mechanisms. Small scale industries, farmer producer organizations, and innovative farmers have to be involved for enhancing large scale production and diffusion. Decentralized production and sale points will address the issue of short life span of these biopesticides and enhance the confidence and trust of the farming community. Social certification by the farming community also acts as a kind of quality control measure. The ongoing government schemes to promote start-ups and agribusinesses may be harnessed. Government of India is promoting Self reliant India. Promotion of organic agriculture and use of these products will serve many objectives of employment generation, local India, and enhancing sustainability of agriculture.

7) The benefits of biopesticides have to be looked not just at farmers' level but at the broader levels of sustainable eco-friendly agriculture/agro ecosystem and ecosystem services.

\section{Conclusion}

The future of microbial biocontrol of plant diseases and how this modern technology can be transferred from lab to land is a big challenge at global level. Although, after so many years of intensive research and despite all the success stories of biocontrol science, it is evident that the number of commercially available biocontrol products is far lower than chemical counterparts. It can be stated that the commercialization of biocontrol products is far behind due to the inappropriate policies and tedious registration process globally. Thus, it is vital for the policy makers to facilitate the registration process and at the same time be stringent enough to regulate the spurious products in the market. Moreover, biocontrol research will only be blue-sky research if trust and awareness among the farmers are lacking. Thus, government, industries, and academia should join hands in sensitizing the farmers to adopt eco-friendly and sustainable farming practices and agri-inputs. Also countries like India are vastly dependent upon agriculture for not only feeding their populations but also for the economy which depends majorly on this sector. However, most of the challenges related to promotion of bioformulations/biopesticides are fundamental. These include the efficacy of the microbial activity, survival of microorganisms, delivery systems, determining host range, avoiding injury to nontarget organisms, consistency, performance in field conditions, economics, government regulations, and confidence among the end users. Biologist has described the future of biocontrol in Asia, and according to him unreasonable expectations for performance, 
inappropriate regulatory guidelines, lack of documentation on the uptake of microbial control strategies, difficulties in implementing local production schemes, and inhibition of scientific exchange are the main hurdles in establishment of biocontrol. In spite of all these limitations, biopesticides are gradually becoming popular around the world. We are confident in our assessment that the industry will continue to grow in the future. The applications of biopesticides/biostimulants have a bright future.

Acknowledgements Authors sincerely acknowledge the Director, ICAR-Central Arid Zone Research Institute, Jodhpur, India for providing all the logistic support required for executing the research work.

\section{Declarations}

Competing Interests The authors declare no competing interests.

Human and Animal Studies We confirm that in this research any human and/or animals participant was not used and there is no any disagreement with informed consent.

\section{References}

1. Lodha S, Gupta GK, Singh S (1986) Crop disease situation and some new records in Indian arid zone. Ann. Arid Zone 25:311-320

2. Mawar R (2001) Influence of on-farm waste on survival of Macrophomina phaseolina (Tassi) Goid., and Fusarium oxysporum f. sp. cumini Prasad and Patel in aridisols, Ph.D Thesis, JNV Uni. p 132

3. Lodha S, Harsh LN (2009) Combined effects of biocontrol agents and residues on root rot mortality in Indian mesquite (Prosopis cineraria). Acta Hortic 883:317-322

4. Mawar R, Sharma D, Ram L (2020) Potential of biocontrol agents against Ganoderma lucidum causing basal stem rot in mesquite (Prosopis cineraria) growing in arid region of India. J For Res. https://doi.org/10. 1007/s11676-020-01161-3(ISSN-1007-662X)

5. Lodha S (1996) Influence of moisture conservation techniques on Macrophomina phaseolina population, dry root rot and yield of clusterbean. Indian Phytopathol 49:342-349

6. Lodha S (1995) Soil solarization, summer irrigation and amendments for the control of Fusarium oxysporum f. sp. cumini and Macrophomina phaseolina in arid soils. Crop Prot 14:215-219

7. Mawar R, Lodha S (2002) Brassica amendments and summer irrigation for the control of Macrophomina phaseolina and Fusarium oxysporum f. sp. cumini in hot arid region. Phytopathol Mediterr 41:45-54

8. Lodha S, Sharma SK, Mathur BK, Aggarwal RK (2003) Integrating sub-lethal heating with Brassica amendments and summer irrigation for control of Macrophomina phaseolina. Plant Soil 256:423-430

9. Mawar R, Lodha S (2009) Efficacy of weed residues vis-a-vis their composts on survival of Macrophomina phaseolina and dry root rot incidence on clusterbean. Indian Phytopathol 62:119-121

10. Bareja M, Mawar R, Mathur M, Lodha S (2010) Effect of composts on microbial population dynamics and activity, dry root rot severity and seed yield of cowpea in Indian arid region. Phytopathol Mediterr 49:381392

11. Mawar R, Lodha S (2006) Relative efficacy of on-farm weeds as soil —amendment for managing dry root rot of clusterbean in an arid environment. Phytopathol Mediterr 45:215-224

12. Lodha S, Solanki KR (1993) Inheritance of dry root resistance in clusterbean. Indian Phytopathol 45:430433

13. Singh MR, Lodha S (2012) Combined effect of biocontrol agents and soil amendments on soil microbial populations, plant growth and incidence of charcoal rot on cowpea and wilt on cumin. Phytopathol Mediterr 51(2):307-316

14. Lodha S, Mawar R, Chakarbarty PK, Singh B (2013) Managing Macrophomina phaseolina causing dry root rot of legumes by a native strain of Bacillus firmus. Indian Phytopathol 66(4):356-360

15. Mishra J, Arora N (2016) Bioformulations for Plant Growth Promotion and Combating Phytopathogens: A Sustainable Approach. In: Bioformulations: for Sustainable Agriculture, pp 3-33. https://doi.org/10.1007/ 978-81-322-2779-3_1 
16. Sood M, Kapoor D, Kumar V, Sheteiwy Mohamed S, Ramakrishnan M, Landi M, Araniti F, Sharma A (2020) Trichoderma: the secrets of multitalented biocontrol agent. Plants 9:762. https://doi.org/10.3390/ plants 9060762

17. Lodha S, Mawar R (2010) Efficacy of native bio-control agents on soil microflora, dry root rot incidence and seed yield of rainfed arid crops. Indian Phytopathol 61:313-317

18. Singh V, Lodha S (2007) Biocontrol Potentials of species of Aspergillus in managing plant pathogens. In: Trivedi PC (ed) Biocontrol of Plant Diseases. Avishkar Publisher, pp 164-184

19. Mawar R, Tomer AS, Singh D (2018) Demonstration of bio-formulated products of bio agents against disease incidence and seed yield of crops in Indian arid region. Indian Phytopathol 71:1-6

20. Mawar R, Tomer AS, Singh D (2019) Demonstration of efficacy of bio-control agents in managing soilborne diseases of various crops in arid region of India. In special issue of Fusarium. Indian Phytopathol 72 : 699-703

21. Berg G, Eberl L, Hartmann A (2005) The rhizosphere as a reservoir for opportunistic human pathogenic bacteria. Environ Microbiol 7:1673-1685

22. Akanksha S, Sarma BK, Upadhyay RS, Singh HB (2012) Compatible rhizosphere microbes mediated alleviation of biotic stress in chickpea through enhanced antioxidant and phenylpropanoid activities. Microbiol Res 168:33-40

23. Jain A, Singh S, Sarma BK, Singh BH (2012) Microbial consortium-mediated reprogramming Of defence network in pea to enhance tolerance against Sclerotinia sclerotiorum. J Appl Microbiol 112(3):537-50. https://doi.org/10.1111/j.1365-2672.2011.05220.x.

24. Köberl M, Ramadan EM, Robmann B, Staver C, Fürnkranz M, Lukesch B, Grube M, Berg G (2012) Using ecological knowledge and molecular tools to develop effective and safe biocontrol strategies. In: Pesticides in the Modern World/Book 5. E-book, Rijeka

25. Van der Heijden MGA, Klironomos JN, Ursic M, Moutoglis P, Streitwolf-Engel R, Boller T, Wiemken A, Sanders IR (1998) Mycorrhizal fungal diversity determines plant biodiversity, ecosystem variability and productivity. Nature 396:69-72

26. Latz E, Eisenhauer N, Rall BC, Allan E, Roscher C, Scheu S, Jousset A (2012) Plant diversity improves protection against soil-borne pathogens by fostering antagonistic bacterial communities. J Ecol 100:597604

27. Mazzola M (2002) Mechanisms of natural soil suppressiveness to soilborne diseases. Antonie Van Leeuwenhoek 81:557-564

28. Weller DM, Raaijmakers JM, McSpadden Gardener BB, Thomashow LS (2002) Microbial populations responsible for specific soil suppressiveness to plant pathogens. Annu Rev Phytopathol 40:309-348

29. Mendes R, Kruijt M, de Bruijn I, Dekkers E, van der Voort M, Schneider JHM, Piceno YM, DeSantis TZ, Andersen GL, Bakker PA (2012) Deciphering the rhizosphere microbiome for disease-suppressive bacteria. Science 332:1097-1100

30. Schmid F, Moser G, Müller H, Berg G (2011) Functional and structural microbial diversity in organic and conventional viticulture: organic farming benefits natural biocontrol agents. Appl Environ Microbiol 77: 2188-2191

31. Grube M, Cardinale M, Vieira de Castro Junior J, Müller H, Berg G (2009) Species-specific structural and functional diversity of bacterial communities in lichen symbiosis. ISME J 3:1105-1115

32. Hossain ST, Chang J and Tagupta VJF (2021). Developments in organic sector in Asia in 2020 p198-2015. In Proceedings : The world of organic agriculture - statistics and emerging trends 2021, (Eds: Willer et al) Research Institute of Organic Agriculture FiBL, Frick, Switzerland and IFOAM Organics International, Bonn, p.340

33. Kranthi KR, Russell D, Wanjari R, Kherde M, Munje S, Lavhe N, Armes N (2002) In-season changes in resistance to insecticides in Helicoverpa armigera (Lepidoptera: Noctuidae) in India. J Econ Entomol 95(1): 134-142. https://doi.org/10.1603/0022-0493-95.1.134

34. Mishra J, Dutta V, Arora NK (2020) Biopesticides in India: technology and sustainability linkages. 3 Biotech 10:210. https://doi.org/10.1007/s13205-020-02192-7

35. Suresh K (2012) Biopesticides: A need for food and environmental safety. J Biofertil Biopestic 3:107

36. Anonymous (2021) One District One Product Scheme. Ministry of Food Processing Industries, Government of India. https://mofpi.nic.in/sites/default/files/odop_list_of_35_states_and_uts.pdf. Accessed 20 Mar 2021

37. NAAS (2013) Biopesticides - Quality Assurance. Policy Paper No. $\overline{62}$. New Delhi

38. Anonymous (2021). Bio-pesticide registrant. Central insecticides Board and Registration committee, Directorate of Plant Protection, Quarantine and Storage, Department of Agriculture, Cooperation and Farmers Welfare, (CIB\&RC) Government of India. http://ppqs.gov.in/divisions/cib-rc/biopesticideregistrant. Accessed 20Mar 2021 
39. de la Cruz R, Cruz Maldonado JJ, Rostro Alanis MJ, Torres JA, Parra Saldivar R (2019) Fungi-based biopesticides: shelf life preservation technologies used in commercial products. J Pest Sci 92(3):1003-1015. https://doi.org/10.1007/s10340-019-01117-5

40. Singh HB, Keswani C, Bisen K, Sarma BK, Chakrabarty PK (2016) Development and application of agriculturally important microorganisms in India. In: Singh HB, Sarma B, Keswani C (eds) Agriculturally Important Microorganisms. Springer, Singapore. https://doi.org/10.1007/978-981-10-2576-1_10

41. Burman U, Manjunatha BL (2017) IPR and Issues Related to Commercialization of Technologies in Agriculture. In: Compendium of Lectures, National Training Course on "Supply chain management and marketing of cereals, legumes and horticulture produce in Indian dry land", 06-10 November, 2017. ICARCAZRI, pp 142-154

42. ICAR (2018) ICAR Guidelines for Intellectual Property Management and Technology Transfer/ Commercialization (Revised in 2018). Indian Council of Agricultural Research, New Delhi Available at https://icar.org.in/sites/default/files/ICAR\%20Guidelines\%20for\%20IPM\%20and\%20Technology\% 20Transfer_2018-1.pdf. Accessed 20 Mar 2021

43. Singhal V (2004) Biopesticides in India. In: Kaushik N (ed) Biopesticides for sustainable agriculture, prospects and constraints. TERI, Delhi, pp 31-39

44. Desai S, Kumar GP, Amalraj ELD, Talluri VR, Peter AJ (2016) Challenges in regulation and registration of biopesticides: an overview. In: Singh DP, Singh HB, Prabha R (eds) Microbial inoculants in sustainable agricultural productivity. Springer, New Delhi, pp 301-308

45. Kulshrestha S (2004) The status of regulatory norms for biopesticides in India. In: Kaushik E (ed) Biopesticides for sustainable agriculture: prospects and constraints. Energy Research Institute, New Delhi 